\title{
Creating Memory: Reading a Patching Language
}

\author{
Michael Barkl \\ Illawarra Institute, Wollongong NSW Australia
}

\begin{abstract}
Musical analysis from score, particularly of structural principles used by the composer, is an area fraught with potential errors caused by conjecture and interpretation. Analysis of music composed using a computer patching language may, alternatively, provide a far more reliable document of a composer's methods. This paper examines a small number of patches created using Miller Puckette's Pure Data (Pd), composed as part of a series of large scale electronic pieces.
\end{abstract}

Keywords: Music composition; electronic music; Pure Data; Pd.

\section{Introduction}

Some years ago I analysed a complex piece of instrumental music written by a well known $20^{\text {th }}$ century Italian composer ${ }^{1}$. The chamber work, for flute, clarinet, violin, cello and piano, crammed with virtuosic fast notes, was known to be completely and systematically derived from a fragment of music taken from a single bar of a piano piece by an even more famous composer ${ }^{2}$.

How did all those notes come from that small fragment?, I asked myself. If I could find out, the mysteries of musical development would become apparent to me, so I thought.

I had the recording and the musical score. The recording gave me the sound of the work; the notation showed me how those sounds were made. However, what was missing was what I desperately wanted: what organising principles did the composer use? How did all those notes, so exciting and beguiling, relate together as an artistic whole?

The analysis I eventually made answered these questions to my own satisfaction. However, the process took me four years, which is not a particularly efficient use of time for a nine-minute piece (an average of two and a quarter minutes of progress per year). At that rate my lifetime would be too short to scarcely begin investigating the number of pieces that interested $\mathrm{me}^{3}$.

${ }^{1}$ Michael Barkl, Franco Donatoni's Etwas ruhiger im Ausdruck (1967), MM dissertation, University of New England, 1986.

${ }^{2}$ The first three beats of the eighth bar of the second of Arnold Schoenberg's Five Piano Pieces (Op 23, 1923).

${ }^{3}$ My next attempt was even less efficient: I spent eight years analysing a seven-minute piece. See, Michael Barkl, Vertigo: Riccardo Formosa's Composition Technique, PhD dissertation, Deakin University, 1994. 
Barely one year after I completed my analysis, a professor of musicology at the Sorbonne published his analysis of precisely the same work ${ }^{4}$.

To be sure, there were some aspects of his analysis that were almost identical to mine. However, there were other conjectures and interpretations that were completely unrelated. Indeed, the differences were so startling that a comparison and discussion of the two analyses occupied almost half a recent doctoral dissertation from Cornell University ${ }^{5}$.

My confidence in the power of analysis, even of systematic creative processes, was severely shaken. If only we could be more sure...

\section{Patching Language as Evidence of Process}

Some four or five years ago I began composing electronic music using the open source patching language Pure Data (Pd) developed by Miller Puckette. ${ }^{6}$ The first thing that struck me about Pd's patching language was its ability to document compositional algorithms. It seemed to me that, with a little care, $\mathrm{Pd}$ patches would be easily readable, not so much as a finished or publishable "score", but as a documentation of a composer's sketches and evidence of process; that is, serving as a kind of descriptive analysis of the piece ${ }^{7}$.

I completed a series of three large-scale electronic works, entitled Music of Grace, which used sine tones only ${ }^{8}$. Examples of patches from The cat dances and the moon shines brightly, the first work of the series, follow, which show some basic aspects of the principle in action. In Figure 1 data flows down the page from panel 1 to panel 5 . The [bang) GUI signals that the previous section is complete as well as initiating the next section ${ }^{9}$.

${ }^{4}$ Robert Piencikowski, "Sauf-conduit (Analyse d'Etwas ruhiger im Ausdruck)", Entretemps, 2 (November 1986), later published as "Salvacondotto. Analisi di Etwas ruhiger im Ausdruck", in Donatoni, ed. Enzo Restagno, Turin: Edizioni di Torino, 1990: 147-158.

${ }^{5}$ Yotam Haber, Aleatory and Serialism in Two Early Works of Franco Donatoni, DMA dissertation, Cornell University, 2004, published as Aleatory and Serialism: Two Early Works of Franco Donatoni, Köln: Lambert Academic Publishing, 2009.

${ }^{6}$ Software by Miller Puckette, http://crca.ucsd.edu/ msp/software.html

${ }^{7}$ Using sketches or examples from a musical score, with minimal annotations, as an analytical tool is well known. Schenker is perhaps the most obvious example of this. See Heinrich Schenker, "Vom Organischen der Sonatenform," in Das Meisterwerk in der Musik, Vol.II, Munich: Drei Masken, 1926; trans. W.Drabkin as "On Organicism in Sonata Form," in The Masterwork in Music, Vol.II, Cambridge University Press, 1996.

${ }^{8}$ Michael Barkl, Composition: Pure data as a Meta-Compositional Instrument, DCA dissertation, University of Wollongong, 2009, published by Köln: Lambert Academic Publishing, 2009.

${ }^{9}$ GUI boxes are rendered [GUI), object boxes are rendered [object], message boxes are rendered [message( and comments are rendered "comment". 


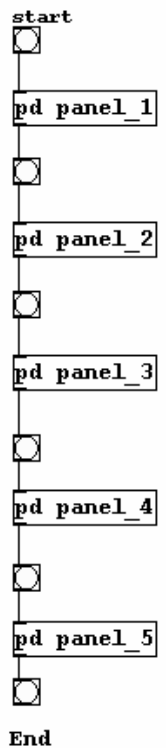

Fig. 1. The cat dances Panels 1-5

Figure 2 shows what is inside the [pd panel_1] sub-patch. Again, data flow is down the page and shows that panel 1 comprises two subsections.

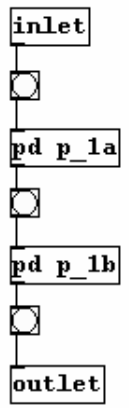

Fig. 2. The cat dances Subsections 1a and $1 \mathrm{~b}$ within Panel 1

Figure 3 shows what is inside the [pd p_1a] sub-patch. Here the data flow is more complex, with feedback to [pd high_control_1-22]. 


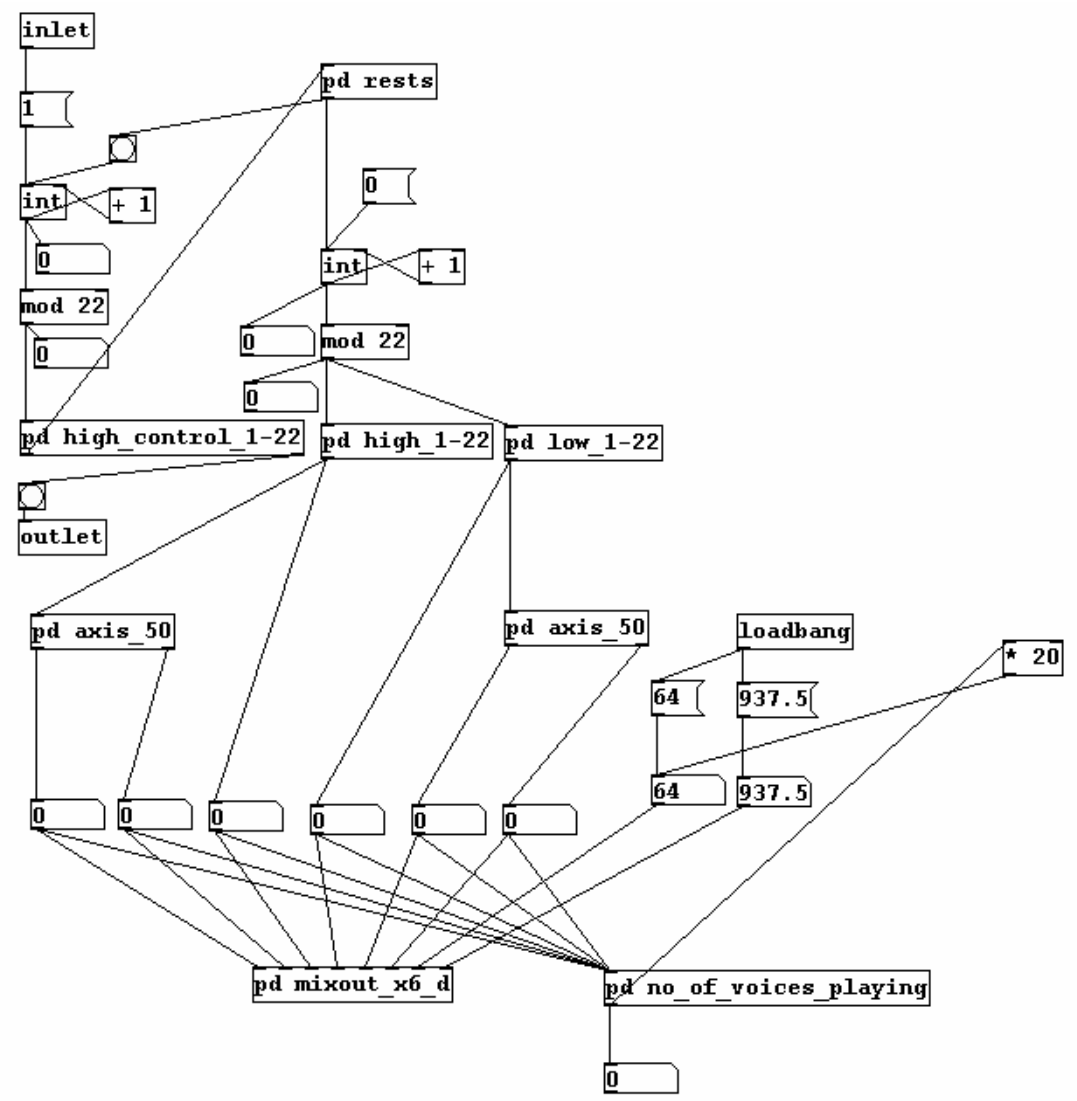

Fig. 3. The cat dances Subsection 1a

Opening further sub-patches, such as [pd high_control_1-22], [pd rests], [pd axis_50], [pd high_1-22], [pd low_1-22], [pd mixout_x6_d] and [pd no_of_voices_playing], would delve deeper into the structure down to the level of elemental operations ${ }^{10}$.

The fifth and final panel of the piece has fewer layers of embedded objects and is thus easier to describe. It applies procedures that control duration, add trills, and direct two musical lines into contrary motion.

A [bang) from the [inlet] begins each side of the patch simultaneously, the left controlling the descending line and the right controlling the ascending line. To discuss the left hand side of the patch first, the [bang) initiates the [int 1][+ 1] counter which advances [pd high_1-22] via [mod 22]. Every output from [pd high_1-22] bangs [pd 0_1_out] in order to alternate the duration of the notes: short $(3700 \mathrm{~ms})$ or long (15000 ms).

At the same time, the output from [pd high_1-22] is sent to the far left hand side of the patch, where the values from [pd high_1-22] are "forced" into an ascending series,

${ }^{10}$ Indeed, this particular piece comprises 50 different patches; the series of three pieces comprises 1025 different patches in total. 


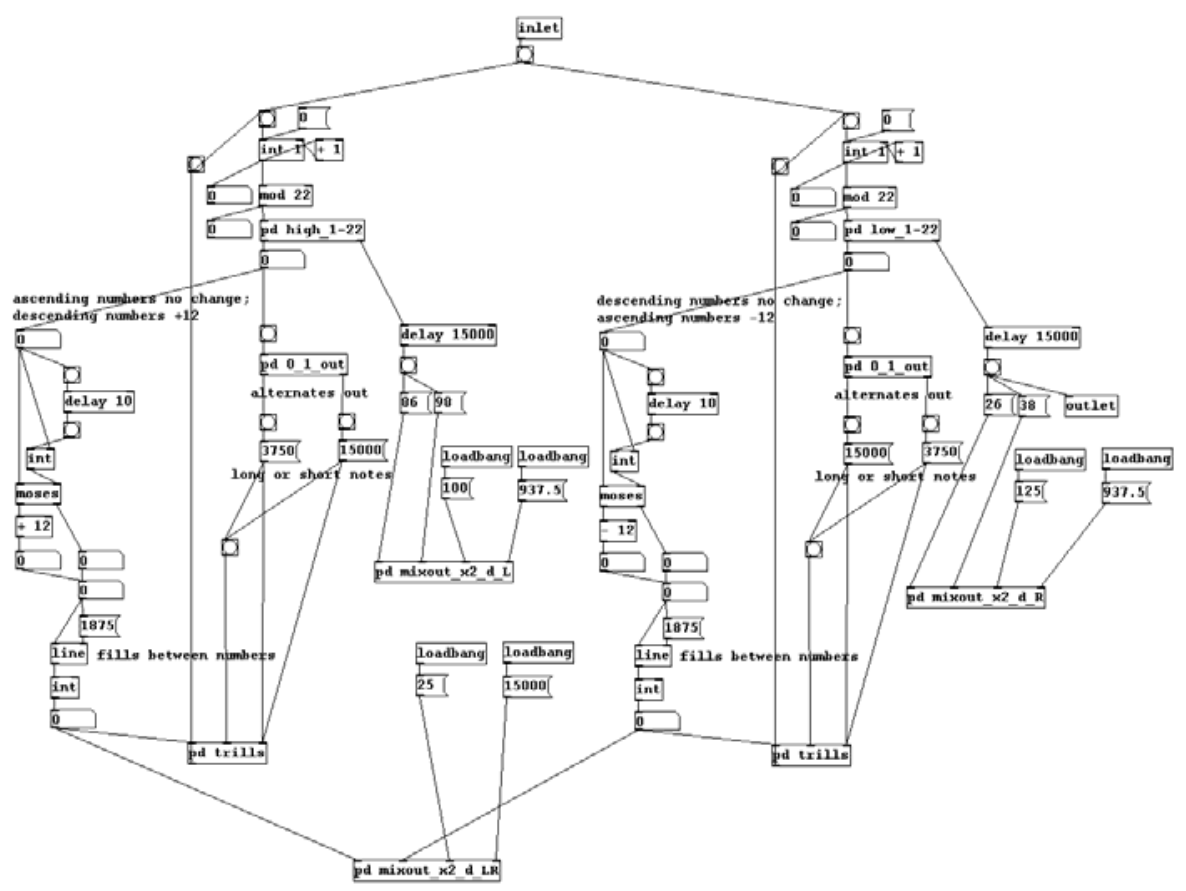

Fig. 4. [pd panel_5]

and then the difference "filled" with integers. This is accomplished by comparing the "new" value with the previous value: every value is slightly delayed by the [delay 10][int] combination of objects in order to seed [moses]. The new value is thereby "compared" with the previous value: if the new value is equal or higher it is sent from the right outlet of [moses]; if it is lower it is sent from the left outlet and 12 is added to it. The [line] object fills the difference between the values over a period of 1875 $\mathrm{ms}$, and these are converted to integers by [int] before being sent to [pd mixout_x2_d] for performance, and to [pd trills] (Figure 5) for the addition of decoration. The output of [pd trills] is sent back to the top of the patch to advance the counter.

The left [inlet] of [pd trills], labelled "Pitch in", receives the values from the [line][int] combination of objects and sends them to two [float]s, adding a value of 2 to the second one. The second and third [inlet]s control the length of the notes by seeding [delay 15000] and then banging it. The second inlet turns on the [toggle) and the output of [delay 15000] turns it off while simultaneously sending a [bang) to the [outlet] to advance the patch as a whole. The [toggle) turns [metro 937.5] on and off, which begins [select 01 1] alternately banging the two [float]s, creating the trill effect.

The right hand side of the [pd panel_5] patch operates in exactly the same way as the left side, except that the values are taken from [pd low_1-22], and the line is "forced" to descend via [-12]. 


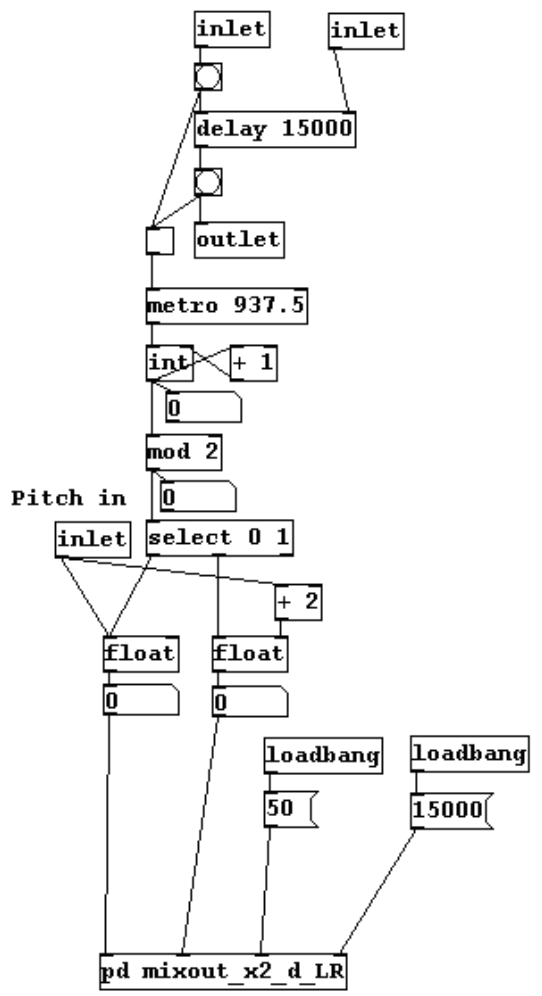

Fig. 5. [pd trills]

The final chord to end the piece is played once the two [pd trills] have banged [pd high_1-22] and [pd low_1-22] enough times for them to have completed their cycle. A bang is sent from the right hand outlet of these objects which, after a delay of $15000 \mathrm{~ms}$, bangs [86( and [98(, routed to stereo left, and [26( and [38(, routed to stereo right, for the final chord.

\section{Conclusion}

The principal motivation for laying out the patches in a clear somewhat linear way has been to clarify my own understanding of the compositional processes taking place in my work by finding a suitable way in which to document them. Indeed, there are many cases in my own previous work where I simply cannot recall the composition process or method.

Nonetheless, visually examining a complex dynamic patch some time after its construction can be challenging, not only to imagine all its events dynamically changing, but to imagine how the outcome of the patch interacts with other patches operating concurrently. Additionally, when describing the patches in this paper, it became clear that even being able to follow the functional operation of a patch or group of patches 
is not the same thing as discerning the musical effect or musical meaning of the composition or even parts of the composition. For this, additional commentary at the "interpretive" level (as distinct from the "descriptive" level) will always be necessary. Nonetheless, it was shown that it is possible for a composition in $\mathrm{Pd}$ to explicitly show its own construction and interrelation of compositional elements, providing a kind of descriptive analysis of the work.

However, the importance of this particular way of using the patching language lies in the potential or capacity for artistic development, improvement and refinement. That is, I, a composer, am much more likely to develop consistently if I am not struggling to remember the last thing I did. For me, therefore, the value of the documentation of composition process is one of memory and recall, irrespective of the genre in which I happen to work. Additionally, it is conceivable that the documentation of the creative process might, some day, be of value to the interested listener, musicologist or even composition student.

\section{References}

1. Barkl, M.: Franco Donatoni's Etwas ruhiger im Ausdruck. MM dissertation. University of New England (1986)

2. Barkl, M.: Vertigo: Riccardo Formosa's Composition Technique. PhD dissertation, Deakin University (1994)

3. Barkl, M.: Composition: Pure data as a Meta-Compositional Instrument. Lambert Academic Publishing, Köln (2009)

4. Haber, Y.: Aleatory and Serialism: Two Early Works of Franco Donatoni. Lambert Academic Publishing, Köln (2009)

5. Piencikowski, R.: Salvacondotto. Analisi di Etwas ruhiger im Ausdruck. In: Restagno, E. (ed.) Donatoni, pp. 147-158. Edizioni di Torino, Turin (1990)

6. Puckette, M.: Software, http://crca.ucsd. edu/ msp/software.html

7. Schenker, H.: On Organicism in Sonata Form. In: Drabkin, W. (trans.) (ed.) The Masterwork in Music, vol. II. Cambridge University Press, Cambridge (1996) 